\title{
A Meta-analysis of Transanal Endoscopic Microsurgery versus Total Mesorectal Excision in the Treatment of Rectal Cancer
}

\author{
Nasir Zaheer Ahmad, FRCS (Gen) ${ }^{1}$ Muhammad Hasan Abbas, FRCS ${ }^{1}$ Mohamed H. Abunada, FRCS 3 \\ Amjad Parvaiz, FRCS (Gen) ${ }^{4,5}$
}

${ }^{1}$ Department of Surgery, University Hospital Limerick, Limerick, Republic of Ireland

${ }^{2}$ Department of Surgery, Russells Hall Hospital, NHS Trust, West Midlands, Dudley, United Kingdom

${ }^{3}$ Department of Surgery, Hamad Medical Hospital, Doha, Qatar

${ }^{4}$ Faculty of Health Sciences, University of Portsmouth, Portsmouth, England

${ }^{5}$ Department of Colorectal Surgery, Poole NHS Trust, Poole, United Kingdom

\begin{abstract}
Address for correspondence Nasir Zaheer Ahmad, FRCS (Gen), Department of Surgery, University Hospital Limerick, St Nessan's Road, Dooradoyle, Co. Limerick V94 F858, Republic of Ireland (e-mail: nasirzahmad@gmail.com).
\end{abstract}

Surg J (NY) 2021;7:e241-e250.

\begin{abstract}
Keywords

Background Transanal endoscopic microsurgery (TEMS) has been suggested as an alternative to total mesorectal excision (TME) in the treatment of early rectal cancers. The extended role of TEMS for higher stage rectal cancers after neoadjuvant therapy is also experimented. The aim of this meta-analysis was to compare the oncological outcomes and report on the evidence-based clinical supremacy of either technique. Methods Medline, Embase, and Cochrane databases were searched for the randomized controlled trials comparing the oncological and perioperative outcomes of TEMS and a radical TME. A local recurrence and postoperative complications were analyzed as primary end points. Intraoperative blood loss, operation time, and duration of hospital stay were compared as secondary end points.

Results There was no statistical difference in the local recurrence or postoperative complications with a risk ratio of 1.898 and 0.753 and p-values of 0.296 and 0.306 , respectively, for TEMS and TME. A marked statistical significance in favor of TEMS was observed for secondary end points. There was standard difference in means of -4.697 , -6.940 , and -5.685 with $p$-values of $0.001,0.005$, and 0.001 for blood loss, operation

- rectal cancer time, and hospital stay, respectively.

- microsurgery

Conclusion TEMS procedure is a viable alternative to TME in the treatment of early rectal cancers. An extended role of TEMS after neoadjuvant therapy may also be offered

- total mesorectal excision to a selected group of patients. TME surgery remains the standard of care in more advanced rectal cancers.
\end{abstract}

Rectal cancer surgery was historically associated with a high local recurrence rate until the emergence of total mesorectal excision (TME) in 1982. ${ }^{1}$ The concept of TME has been accepted widely and is now considered to be a gold standard in the surgical treatment of rectal cancer. A radical surgery for rectal cancer in the form of a TME is often associated with received

December 29, 2020 accepted after revision July 22, 2021
DOI https://doi.org/

$10.1055 / \mathrm{s}-0041-1735587$.

ISSN 2378-5128. (c) 2021. The Author(s).

This is an open access article published by Thieme under the terms of the Creative Commons Attribution License, permitting unrestricted use, distribution, and reproduction so long as the original work is properly cited. (https://creativecommons.org/licenses/by/4.0/)

Thieme Medical Publishers, Inc., 333 Seventh Avenue, 18th Floor, New York, NY 10001, USA 
the risk of serious perioperative morbidity and mortality and has led to a search for less aggressive alternatives particularly in patients who are unfit and have significant comorbidities.

A transanal endoscopic microsurgery (TEMS) was introduced in 1983 by Buess et al as an alternative to the existing transanal excision techniques used for resection of rectal adenomas. $^{2,3}$ The issues with the traditional transanal excisions were difficult histological interpretation of the surgical specimen because of the operative fragmentation, a high rate of positive margins and especially the inability to access high lying rectal lesions. Early results of TEMS confirmed its ability to excise large circumferential lesions and the lesions as high as $25 \mathrm{~cm}$ with precision and safety. ${ }^{4,5}$ The superiority of TEMS over transanal excisions was accepted and reported in subsequent observational studies and meta-analysis. ${ }^{6,7}$ The indications of TEMS have evolved over the years and consist of a potential role in dilating the colorectal anastomotic strictures, ${ }^{8}$ repair of rectovaginal fistulas, ${ }^{9}$ transanal rectal prolapse surgery, ${ }^{10}$ and its use as a platform for NOTES (Natural Orifice Transluminal Endoscopic Surgery) procedure. ${ }^{11}$

TEMS was also proposed as an alternative to TME in the treatment of early rectal cancer and in situations where a radical surgery would carry a significantly higher risk of complications. There have been experimental attempts to extend the indications of a TEMS to even more advanced rectal cancers by utilizing adjuvant therapies. Several randomized controlled trials (RCTs), observational studies, and meta-analysis have compared the results of TEMS with radical TME in dealing with rectal cancer. ${ }^{12-16}$ A more recent meta-analysis of RCTs comparing the oncological and shortterm outcomes of the two techniques did not find any significant difference in the local recurrence rate between the two techniques. ${ }^{17}$ The current meta-analysis of the RCTs and a literature review was conducted to compare the shortand long-term outcomes of TEMS and a radical TME in the treatment of early rectal cancers which could prove useful for clinical decision-making for practicing colorectal surgeons.

\section{Methods}

A literature search of Medline, Embase, and Cochrane databases was performed using the keywords, "transanal endoscopic microsurgery," OR "total mesorectal excision" AND "rectal cancer." The search was limited to the RCTs. No language or time constraint was applied to the search strategy. Further manual searching was performed of the references for missing studies. All the titles and selected abstracts were reviewed by two authors. Duplicate studies and irrelevant articles were excluded. Full-text articles of more pertinent publications were retrieved and final decisions to include or exclude a study were made with consensus. RCTs comparing the oncological and perioperative outcomes after TEMS or a radical TME were considered suitable for meta-analysis. In cases of more than one publications by the same authors, only the most recent trial was included in the analysis. Data on patient characteristics, study designs, outcomes, and follow-ups were extracted by one of the authors and counterchecked by the second author.
Any discrepancy or disagreement was resolved by input from the senior author. Preferred Reporting Items for Systematic Reviews and Meta-Analyses guidelines were followed for the literature search. ${ }^{18}$

\section{Quality Assessment}

The quality of included RCTs was assessed using Jadad scoring system. ${ }^{19}$ The assessment was performed across different variables to check for randomization, method of randomization, blinding, and description of follow-ups or the dropouts. None of the RCTs was reported as blinded probably because of the nature of the intervention and scored zero in this area of assessment. RCTs meeting all the criteria of randomization, blinding, and follow-up would have a maximum score of 5 . A score of less than 2 would be considered low quality and more than 2 a high quality.

\section{End Points}

The primary end point of local recurrence rate after primary excision was analyzed as a long-term outcome and the postoperative complications related to both techniques were compared as short-term outcomes. Other perioperative outcomes including the hospital stay, operation time, and intraoperative bleeding were also analyzed as secondary end points.

\section{Statistics}

The data from the included RCTs were pooled on the Microsoft Excel. The dichotomous and continuous data were separated for analysis. Heterogeneity among the studies was checked for the primary and secondary outcomes. In case of a significant heterogeneity (a value of $<0.1$ ), a random effect model was used for meta-analysis and vice versa. The risk ratio (RR) and 95\% confidence interval $(\mathrm{CI})$ was calculated for the dichotomous data and standard difference in means (SDM) along with 95\% CI was calculated for the continuous variables. The mean and standard deviation values were estimated using the formulas given by Hozo et al. $^{20} \mathrm{~A}$ publication bias was checked and a sensitivity analysis was done. Comprehensive Meta-Analysis, Version 2 was used for statistics.

\section{Results}

An advanced literature search of Medline, Embase, and Cochrane databases revealed 161, 139 and 74 publications, respectively. After the exclusions of duplicates and other irrelevant publications, three RCTs were found suitable for meta-analysis ${ }^{21-23}$ (- Fig. 1).

A total number of 208 patients with an average age of 64.6 years in the TEMS group and 64.36 years in the TME group were analyzed according to the study protocols. The rest of the study characteristics are given in - Tables $\mathbf{1}$ and $\mathbf{2}$.

Local recurrence was seen in $7 / 103(6.7 \%)$ cases in the TEMS group and 3/105 (2.8\%) in the group after radical TME. There was a significant difference in the follow-up in different trials that explains recurrence of more cases in a trial with longest follow-up. A meta-analysis of local recurrence 


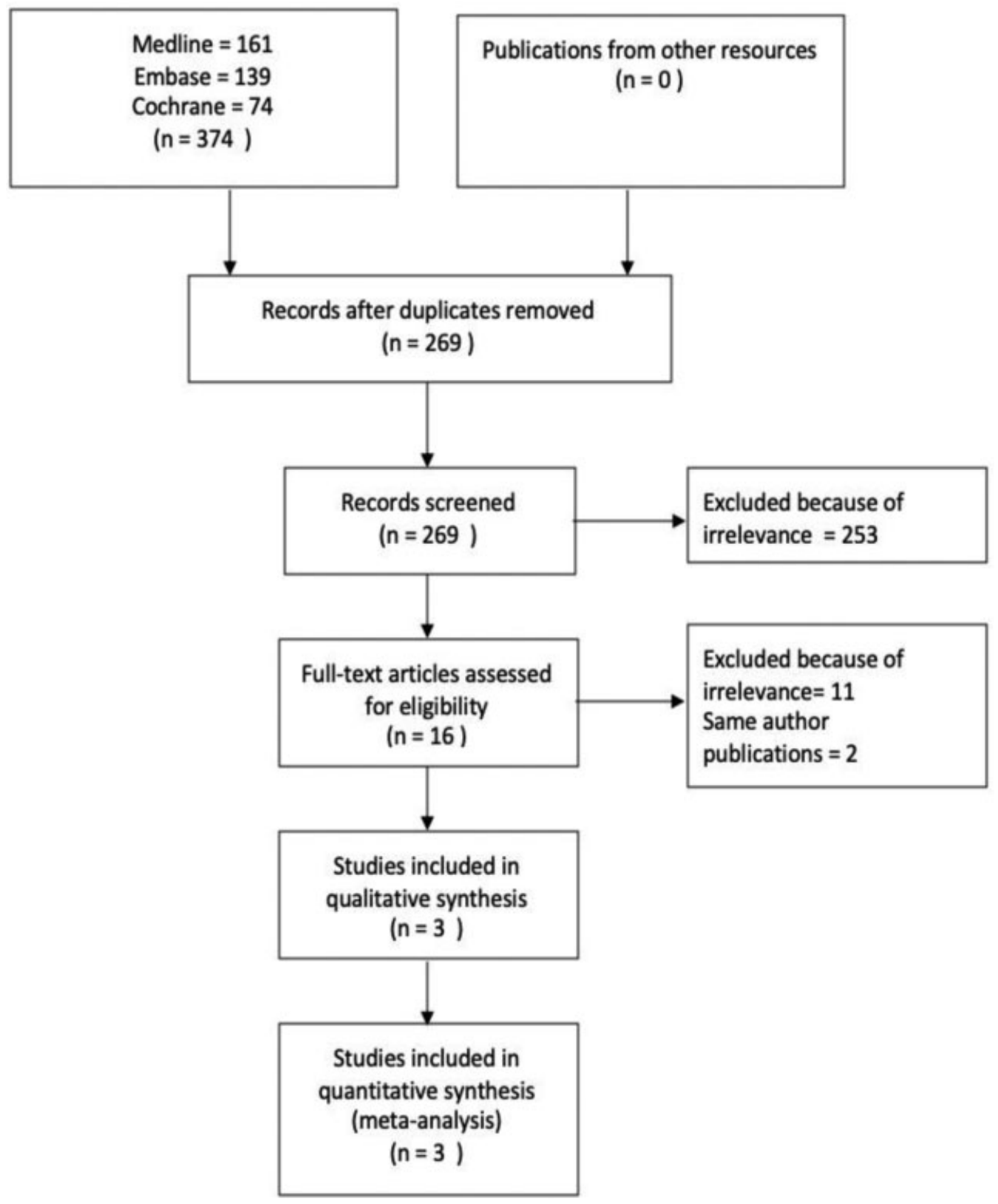

Fig. 1 Preferred Reporting Items for Systematic Reviews and Meta-Analyses flow chart.

after rectal cancer surgery using the fixed effect model did not show any statistical difference between the two groups with an RR of 1.898 and a p-value of 0.296 (-Fig. 2).

Postoperative complication rate was 18/103 (17.47\%) and 25/105 (23.8\%) in the TEMS and the TME groups, respectively. A meta-analysis using the fixed effect model did not show any significant difference between the two groups with an RR of 0.753 and $p$-value of 0.306 (-Fig. 3).

As reported in the literature previously, the hospital stay after the surgery was shorter in patients who underwent a TEMS procedure as compared with the patients who had a radical surgery. The average hospital stay was 6.2 and 13 days for the TEMS and TME groups, respectively. There was significant heterogeneity among the studies and a random effect meta-analysis confirmed a significant difference between the two groups in favor of TEMS. The operating time was much shorter for a TEMS procedure as compared with a radical resection, 107.76 and 173.9 minutes, respectively. There was a significant heterogeneity among the studies and a random effect model showed a significant difference in favor of TEMS. The average intraoperative blood loss was $76.23 \mathrm{~mL}$ in the TEMS group and $346.23 \mathrm{~mL}$ in the TME group. This significant difference is explained by the major bleeds that happened in 11 cases in the radical surgery group only. There was no major bleed in the TEMS group. A random effect meta-analysis favored TEMS and confirmed a significant difference between the two techniques ( - Table 3 ).

\section{Publication Bias}

A publication bias was checked for the primary end point of local recurrence. The funnel plot of the standard error by log odds ratio and $95 \% \mathrm{CI}$ was asymmetrical suggesting a high 
e244 A Meta-analysis of TEMS versus TME in the Treatment of Rectal Cancer Ahmad et al.

Table 1 Study characteristics

\begin{tabular}{|c|c|c|c|}
\hline RCT & Winde et al & Lezoche et al & Chen et al \\
\hline Year & 1996 & 2012 & 2013 \\
\hline Country & Germany & Italy & China \\
\hline Ethical approval & NG & Yes & Yes \\
\hline $\begin{array}{l}\text { Preoperative } \\
\text { investigations }\end{array}$ & $\begin{array}{l}\text { Proctoscopy/biopsies, } \\
\text { colonoscopy, ERUS, biochemical } \\
\text { profile }\end{array}$ & $\begin{array}{l}\text { ERUS, rigid sigmoidoscopy, } \mathrm{CT}, \mathrm{MRI} \text {, } \\
\text { colonoscopy and biopsies, tattoo }\end{array}$ & Rectoscopy, ERUS, CT, MRI \\
\hline Randomization & Number table & Sealed envelopes & Equal randomization \\
\hline Power calculation & Not done & Yes & Not done \\
\hline Jadad scale & 3 & 3 & 2 \\
\hline Cancer stage & $\mathrm{T} 1$ & $\mathrm{~T} 2$ & $\mathrm{~T} 1, \mathrm{~T} 2$ \\
\hline Tumor location & $8-18 \mathrm{~cm}$ & $6 \mathrm{~cm}$ & $6-15 \mathrm{~cm}$ \\
\hline Tumor size & NG & $<3 \mathrm{~cm}$ & $<3 \mathrm{~cm}$ \\
\hline Preoperative histology & Adenocarcinoma (G1/2) & $\begin{array}{l}\text { Well or moderately well-differentiated } \\
\text { carcinoma }\end{array}$ & $\begin{array}{l}\text { Moderate or highly differentiated } \\
\text { carcinoma }\end{array}$ \\
\hline Postoperative histology & Not reported & Not reported & Reported \\
\hline Inclusion & $\begin{array}{l}\text { Adenocarcinoma } \mathrm{G} 1 \text { and } \mathrm{G} 2 \\
\mathrm{~T} 1 \text { tumors }\end{array}$ & $\begin{array}{l}\text { ASA I and II, within } 6 \mathrm{~cm} \text { of anal verge, well } \\
\text { (G1) or moderately }(G 2) \text { differentiated, less } \\
\text { than } 3 \mathrm{~cm} \text { diameter }\end{array}$ & $\begin{array}{l}\text { No previous lower abdominal or } \\
\text { pelvic surgery } \\
\text { Acceptable physical status }\end{array}$ \\
\hline Exclusions & $\begin{array}{l}\text { Poorly differentiated tumors, } \\
\text { higher than T1 stage }\end{array}$ & $\begin{array}{l}\text { ASA III and IV, more proximal tumor, poorly } \\
\text { (G3) or undifferentiated (G4) tumors, } \\
\text { tumors with lymphovascular or perineural } \\
\text { invasion, suspicious lymph node status }\end{array}$ & $\begin{array}{l}\text { Deep tumor invasion } \\
\text { Distant metastasis }\end{array}$ \\
\hline Confounders & NG & NG & $\begin{array}{l}\text { Hypertension, DM, cardiovascular } \\
\text { disease }\end{array}$ \\
\hline CRT & None & All & None \\
\hline Bowel preparation & Yes & Yes & NG \\
\hline Number of surgeons & 3 & 2 & NG \\
\hline Antibiotics & Yes & Yes & NG \\
\hline Patients & 50 & 100 & 60 \\
\hline TEMS resection margin & $1 \mathrm{~cm}$ & NG & $0.5-1 \mathrm{~cm}$ \\
\hline TME resection margin & $2 \mathrm{~cm}$ & NG & $2 \mathrm{~cm}$ \\
\hline $\begin{array}{l}\text { Frozen section } \\
\text { (TEMS/TME) }\end{array}$ & None & None & Yes \\
\hline Ileostomy & NG & 23 (11 temporary 12 permanent after APR) & 9 \\
\hline Rectal perforations & 1 & None & 2 \\
\hline $\begin{array}{l}\text { Conversion from TEMS } \\
\text { to TME }\end{array}$ & 0 & 0 & 2 \\
\hline $\begin{array}{l}\text { Violation of study } \\
\text { protocol }\end{array}$ & NG & 6 & NG \\
\hline Access & Open & Laparoscopic & Laparoscopic \\
\hline Drain & Yes & Yes & NG \\
\hline $\begin{array}{l}\text { Investigations at follow- } \\
\text { up }\end{array}$ & $\begin{array}{l}\text { Proctoscopy, tumor markers, } \\
\text { clinical examination, CXR, ERUS } \\
\text { every } 3 \text { mo for } 2 \text { y and then } \\
\text { biannually for } 3 \text { y. Annual after } 5 \text { y }\end{array}$ & $\begin{array}{l}\text { Tumor markers, clinical examination, } \\
\text { sigmoidoscopy } 3 \text { monthly for } 3 \mathrm{y} \text {, then } 6 \\
\text { monthly, CT/MRI biannually for } 5 \mathrm{y}\end{array}$ & $\begin{array}{l}\text { Tumor markers, USG, CXR } \\
\text { biannually } \\
\text { CT/MRI, colonoscopy annually }\end{array}$ \\
\hline End points & $\begin{array}{l}\text { Local and distant recurrences, } \\
\text { complications, hospital stay, blood } \\
\text { loss, operation time, analgesia } \\
\text { requirements, survival rate, and } \\
\text { mortality }\end{array}$ & $\begin{array}{l}\text { Local and systemic recurrences, operation } \\
\text { time, blood loss, analgesic use, morbidity, } \\
\text { hospital stay, 30-d mortality }\end{array}$ & $\begin{array}{l}\text { Operative time, blood loss, } \\
\text { recovery time, morbidity, } \\
\text { mortality, local recurrence, distant } \\
\text { recurrence }\end{array}$ \\
\hline
\end{tabular}

Abbreviations: APR, abdominoperineal resection; ASA, American Society of Anesthesiologists; CRT, chemoradiotherapy; CT, computed tomography; CXR, chest X-ray; ERUS, endorectal ultrasound; MRI, magnetic resonance imaging; NG, not given; RCT, randomized controlled trial; TEMS, transanal endoscopic microsurgery; TME, total mesorectal excision. 
Table 2 Study characteristics

\begin{tabular}{|c|c|c|c|c|c|c|}
\hline \multirow[t]{2}{*}{ RCT } & \multicolumn{2}{|l|}{ Winde et al } & \multicolumn{2}{|l|}{ Lezoche et al } & \multicolumn{2}{|l|}{ Chen et al } \\
\hline & TEMS & TME & TEMS & TME & TEMS & TME \\
\hline Number of patients & 24 & 26 & 50 & 50 & 30 & 30 \\
\hline Average age & 63.7 & 60.9 & $60 \pm 3$ & $66 \pm 2.25$ & $68.8 \pm 5.3$ & $66.2 \pm 7.7$ \\
\hline Secondary operations & 2 & 3 & 1 & 3 & 0 & 0 \\
\hline Salvage surgery & 1 & 0 & NG & NG & 1 & 0 \\
\hline $\mathrm{BMI}$ & NG & NG & NG & NG & $20.0 \pm 0.3$ & $20.1 \pm 0.3$ \\
\hline Conversions & 0 & 0 & 0 & 5 & 2 & 0 \\
\hline Major bleeding & 1 & 0 & 0 & 10 & 0 & 1 \\
\hline Positive margin & NG & NG & 0 & 0 & 0 & 0 \\
\hline Margins & $1 \mathrm{~cm}$ & $2 \mathrm{~cm}$ & $1 \mathrm{~cm}$ & NG & $0.5-1 \mathrm{~cm}$ & $2 \mathrm{~cm}$ \\
\hline Lymph nodes retrieved & NG & NG & 1 & 11 & NG & NG \\
\hline Follow-up & $40.9 \pm 24.6$ & $45.8 \pm 24.6$ & $9.6 \pm 1.72 Y$ & $9.6 \pm 1.9 \mathrm{Y}$ & $18.0 \pm 2.6$ & $17.5 \pm 2.2$ \\
\hline Mortality & 1 & 1 & 10 & 7 & 0 & 0 \\
\hline Tumor distance & NG & NG & $4.92(3-6)$ & $5(3-6)$ & $7.8 \pm 1.6$ & $8.1 \pm 1.3$ \\
\hline Tumor size & NG & NG & NG & NG & $2.3 \pm 0.5$ & $2.8 \pm 0.6$ \\
\hline T1 & 24 & 26 & 0 & 0 & $24 / 30$ & $22 / 30$ \\
\hline $\mathrm{T} 2$ & 0 & 0 & 50 & 50 & $6 / 30$ & $8 / 30$ \\
\hline T stage under estimation & Not reported & Not reported & Not reported & Not reported & 2 & 0 \\
\hline $\begin{array}{l}\text { Lymphovascular invasion on } \\
\text { postoperative specimen }\end{array}$ & NG & NG & NG & NG & 4 & 7 \\
\hline Adjuvant chemotherapy & NG & NG & 0 & 0 & 1 & 8 \\
\hline
\end{tabular}

Abbreviations: BMI, body mass index; NG, not given; RCT, randomized controlled trial; TEMS, transanal endoscopic microsurgery; TME, total mesorectal excision.

possibility of publication bias (-Fig. 4). A classic fail-safe $\mathrm{N}$ method confirmed the bias and it was established that as the difference between two methods was not significant, no more studies would be required to bring the $p$-value to $>0.05$. A sensitivity analysis did not have any effect on the results.

\section{Discussion}

TEMS was proposed to treat benign adenomas, not accessible with the conventional instruments for transanal local excision. A high rate of incidental cancers in the postoperative specimens led the surgeons to extend the indications of TEMS for early rectal cancer with anticipated lower risk of recurrence. ${ }^{24}$ Low-risk cancers defined as those limited to the submucosa (T1), less than $3 \mathrm{~cm}$ in size, exhibit well to moderately differentiated morphology, are Sm1, Haggitt 1-3 and do not show any lymphovascular invasion. ${ }^{25}$ The RCTs included in this meta-analysis adapted extensive investigations for accurate preoperative staging of rectal cancers.

The preoperative investigations commonly employed to characterize a rectal cancer include digital rectal examination, rectoscopic biopsies, endorectal ultrasound, magnetic resonance imaging (MRI), and computed tomography of thorax, abdomen, and pelvis to exclude distant metastasis.
Endorectal ultrasound and MRI are considered sensitive and diagnostic for the depth of tumor invasion and assessment of regional lymph nodes. However, in a vast majority of the cases, the accurate stage of the tumor could only be determined after the final histology of the excisional specimen. ${ }^{26}$ A discrepancy in the preoperative and postoperative histological diagnoses is not uncommon. As a result of this inconsistency, some low-risk early rectal cancers may get operated with radical resections ${ }^{27}$ and vice versa. Postoperative pathological stage and a comparison with the preoperative stage were only reported in one of the trials included in this meta-analysis. ${ }^{23}$

The outcomes of TEMS depend on proper patient selection which does include selection of a suitable cancer as well. A suitable patient with unsuitable cancer or a suitable cancer with an unsuitable patient are the possible clinical scenarios which would have impact on the outcomes. A radical TME on the other hand does not suffer from this constraint and almost every rectal cancer can be subjected to this type of operation. A careful selection of the cases has been emphasized for optimal outcomes when TEMS is attempted with a curative intent. $^{28}$ But even a careful selection of the cases may still lead to less than satisfactory results and a radical resection in the form of a TME may still be necessary in 30\% of the cases after initial TEMS. ${ }^{29}$ 


\section{Local Recurrence}

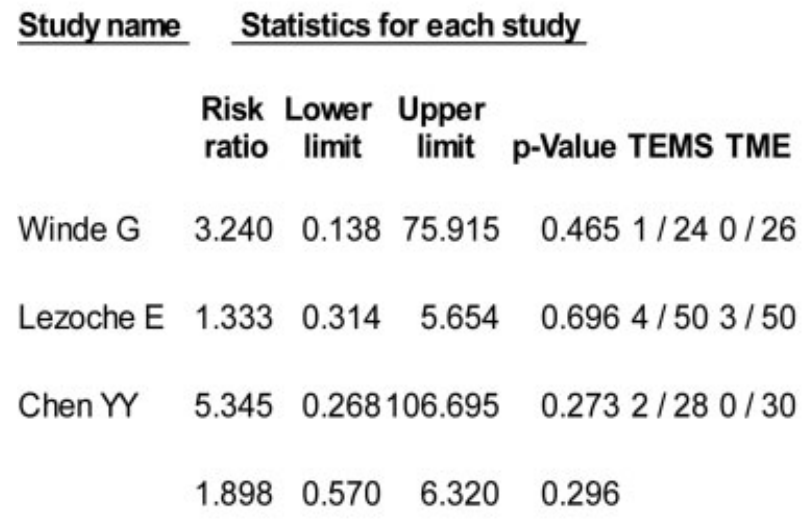

\section{Risk ratio and $95 \% \mathrm{Cl}$}

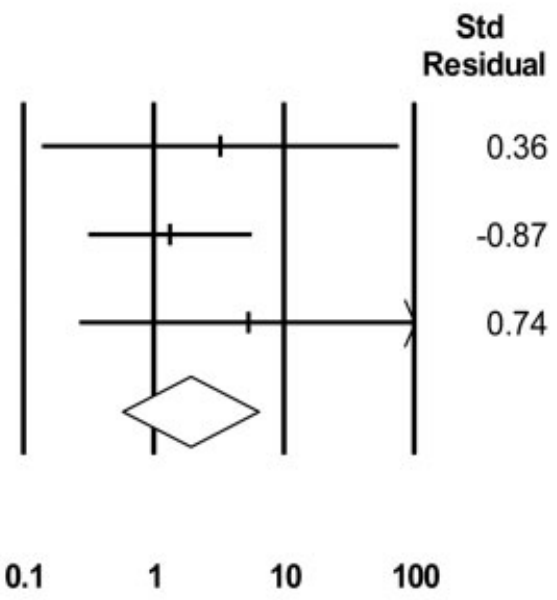

Favours TEMS Favours TME

The test of heterogeneity showed a Q-value. 0.788, df(Q). 2, P-value. 0.674 and I-squared. 0.001. A fixed effect meta-analysis revealed an odds ratio of 1.898 with $95 \%$ confidence interval of 0.570 to 6.320 and a $P$ value of 0.296

Fig. 2 A meta-analysis of local recurrence. TEMS, transanal endoscopic microsurgery; TME, total mesorectal excision.

A completely correct preoperative staging and even a confirmed diagnosis of low-risk early rectal cancer would still not be enough to eliminate the risks of local recurrence and other complications after TEMS. The importance of a careful patient selection for TEMS cannot be overemphasized as salvage procedures would become necessary to treat the recurrences of TEMS. ${ }^{30} \mathrm{~A}$ low-risk T1 rectal cancer may already have involved the regional lymph nodes that would lead to a high recurrence rate if the lymphatic basin is left untreated. ${ }^{31}$ Patients with T1 rectal cancer from the Dutch TME trial when compared with TEMS and TME showed $24 \%$ recurrence rate after TEMS and $80 \%$ of these patients eventually required radical surgery for the local recurrence. ${ }^{32}$

There is a substantial risk of local recurrence especially for large rectal cancers with unfavorable histology. Further treatment of local recurrence depends on the intention to cure or palliate. A TME after the recurrence of TEMS is known to have reasonably good results comparable to primary TME; however, the presence of distant metastasis or the complexity of a salvage procedure would generally have poor prognosis. ${ }^{33-39}$ A recurrence after TEMS may require an abdominoperineal resection (APR) as the salvage procedure and in case of the recurrence involving other pelvic organs, it may become necessary to undertake a pelvic exenteration in which case the outcomes are even poorer. ${ }^{40}$ The disastrous outcomes of a second salvage surgery highlight the importance of careful selection of cases for the primary TEMS. ${ }^{41}$ The outcomes of the salvage resections are not detailed in the studies included in this meta-analysis.

The role of neoadjuvant chemoradiotherapy (CRT) before undertaking TEMS has been reported with promising results even for locally advanced cancers. ${ }^{22,42-44}$ On the other hand, it has been established that a local recurrence is more likely to happen after local excision of T2 or T3 rectal cancers. ${ }^{45}$ The CART study (Transanal Endoscopic Microsurgery After Radiochemotherapy for Rectal Cancer) confirmed similar results and reported that about one-third of patients after CRT and TEMS would still require radical resection. ${ }^{46} \mathrm{~A}$ relatively higher recurrence rate when operated by TEMS after neoadjuvant therapy was reported by one of the RCTs included in this metaanalysis. A 50\% downstaging and downsizing after neoadjuvant therapy is believed to be a prerequisite for TEMS in these cancers and is believed to minimize the risk of recurrence. ${ }^{22}$

The risk of complications other than a local recurrence is not different after radical surgery or TEMS. The spectrum of complications includes immediate postoperative issues such as bleeding, anastomotic breakdown, infection, incontinence or rectal pain, and the functional outcomes impacting on 


\begin{tabular}{|c|c|c|c|c|c|}
\hline \multirow[t]{2}{*}{ Study name } & \multicolumn{5}{|c|}{ Statistics for each study } \\
\hline & $\begin{array}{l}\text { Risk } \\
\text { ratio }\end{array}$ & $\begin{array}{l}\text { Lower } \\
\text { limit }\end{array}$ & $\begin{array}{l}\text { Upper } \\
\text { limit }\end{array}$ & p-Value TEMS & TME \\
\hline Winde G & 0.602 & 0.235 & 1.544 & $0.2915 / 24$ & $9 / 26$ \\
\hline Lezoche E & 0.700 & 0.290 & 1.692 & $0.4287 / 50$ & $10 / 50$ \\
\hline Chen $Y$ & 1.071 & 0.391 & 2.935 & $0.8936 / 28$ & $6 / 30$ \\
\hline & 0.753 & 0.438 & 1.296 & 0.306 & \\
\hline
\end{tabular}

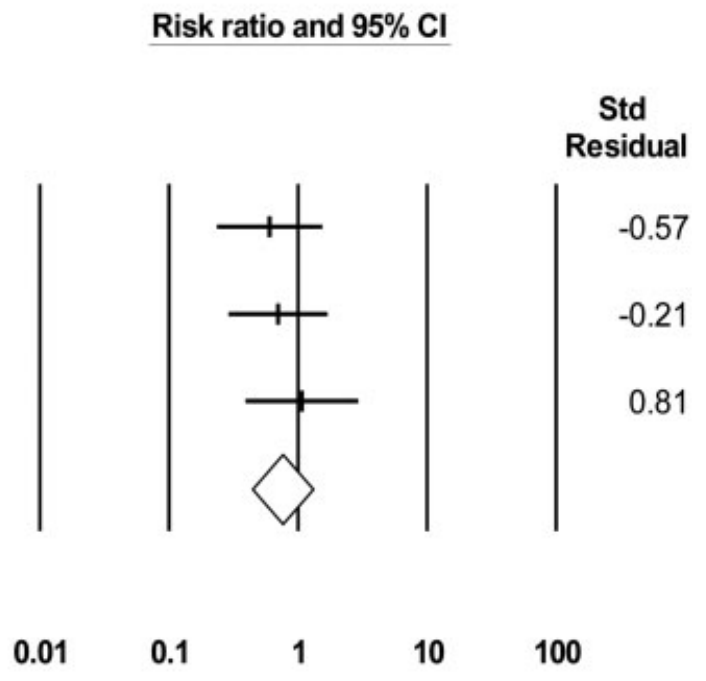

Favours TEMS Favours TME

The test of heterogeneity showed a Q-value. 0.714, df(Q). 2, P-value. 0.699 and I-squared. 0.001. A fixed effect meta-analysis revealed an odds ratio of 0.753 with $95 \%$ confidence interval of 0.438 to 1.296 and a $P$ value of 0.306

Fig. 3 A meta-analysis of complications. TEMS, transanal endoscopic microsurgery; TME, total mesorectal excision.

quality of life. In addition, a radical surgery may be associated with genitourinary dysfunction and patient may also suffer from the sequelae of an anastomotic leak. Low anterior resection syndrome (LARS), once thought to be a complication, exclusively related to a radical resection for a very low rectal cancer is not entirely true as patients undergoing TEMS have also been reported to suffer from this complication. ${ }^{46,47}$ The quality of life disruption after LARS seems to be transient as a comparison of functional outcomes after TEMS or TME for $\mathrm{T} 1$ rectal cancer revealed a complete recovery in both groups at 1 year. ${ }^{48}$ It has been established that a preoperative CRT and more distal lesions lead to more issues with functional outcomes, but fortunately, these complications are usually self-limiting. ${ }^{49}$ The trials included in this meta- analysis did report on rectal pain and anal incontinence, but the occurrence of LARS as a long-term complication was not reported in any of the publications.

This meta-analysis suffers from some inherent limitations which may have an impact on overall effect size calculations. These include limited number of RCTs with a small number of patients, a significant heterogeneity among the studies, inconsistent inclusion and exclusion criteria, diverse protocols for adjuvant and neoadjuvant therapies, and a different duration of follow-ups. Despite these shortcomings, the meta-analysis of primary end points completely rejected the theoretical assumptions of a higher risk of surgical complications after radical surgery and a higher risk of local recurrence rate after TEMS. There

Table 3 A meta-analysis of the hospital stay, operation time, and blood loss

\begin{tabular}{|l|l|l|l|l|l|l|l|l|l|}
\hline \multirow{2}{*}{ Outcome } & \multirow{2}{*}{ SDM } & \multicolumn{2}{l}{$95 \%$ confidence interval } & \multicolumn{3}{l|}{ Heterogeneity } & \multicolumn{2}{l|}{ Favors } \\
\cline { 3 - 10 } & & Lower & Upper & SE & p-Value & Q-Value & $p$-Value & $I^{2}$ & \\
\hline Hospital stay & -5.685 & -8.131 & -3.239 & 1.248 & 0.001 & 31.387 & 0.001 & 93.628 & TEMS \\
\hline Operation time & -6.940 & -11.793 & -2.087 & 2.476 & 0.005 & 129.71 & 0.001 & 98.458 & TEMS \\
\hline Blood loss & -4.697 & -7.348 & -2.046 & 1.353 & 0.001 & 61.305 & 0.001 & 96.738 & TEMS \\
\hline
\end{tabular}

Abbreviations: SDM, standard difference in means; SE, standard error; TEMS, transanal endoscopic microsurgery. 


\section{Funnel Plot of Standard Error by Log risk ratio}

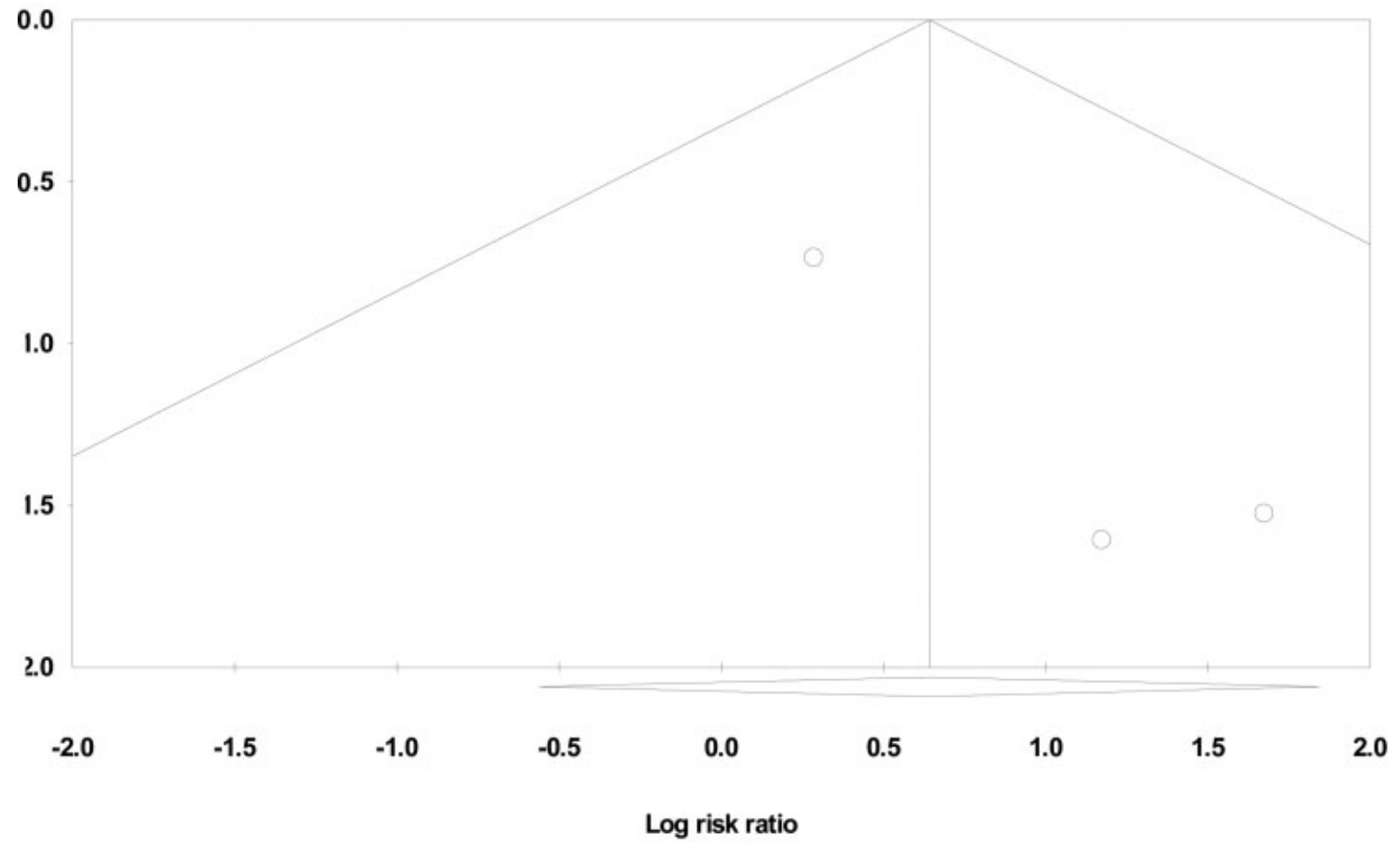

Asymmetrical funnel plot suggesting publication bias. A classic fail-safe $\mathrm{N}$ method showed a Z-value for the observed studies $=1.280$. P-value for the observed studies $=0.200$, Alpha $=0.05$, Tails $=2, \mathrm{Z}$ for alpha $=1.959$, Number of observed studies $=3$, Number of missing studies that would bring $\mathrm{p}$-value to $>$ alpha $=0$

Fig. 4 Funnel plot of publication bias.

was a difference in the surgical approach across the included studies as Winde et $\mathrm{al}^{21}$ used an open approach for radical resections, whereas laparoscopic resections were performed in the other two trials. ${ }^{22,23}$ A distinct statistical difference in favor of TEMS was observed in secondary end points. A shorter hospital stay and duration of surgery would have an impact on the cost effectiveness of the procedure. Similarly, less blood loss would lead to avoidance of perioperative blood transfusions which is considered relevant in cancer surgery.

\section{Conclusion}

There is no convincing evidence that TEMS is superior to TME in terms of the oncological outcomes, but the organ preservation philosophy sounds promising in the treatment of early rectal cancers, and therefore, it should be offered carefully to very selected patients. ${ }^{50}$ The extended indications of TEMS in dealing with T2 tumors after neoadjuvant therapy seem somewhat presumptuous, as a similar $\mathrm{T}$ stage for radical surgery would go straight for surgery without any neoadjuvant therapy avoiding the hazards of CRT. The argument of a palliative TEMS in patients not fit for a radical surgery seems justified in selected cases but with the evolving concept of wait and watch after CRT, a vigorous surveillance may be another option for these patients. This concept would need more studies to compare the outcomes of two modalities in dealing with these cancers. TEMS definitely has a vital role in the surgical practice but because of the risks of unfavorable outcomes so far in the curative treatment of rectal cancer, this therapeutic modality may be limited to the clinically, radiologically, and histologically proven early rectal cancers.

Ethical Approval

Not applicable.

Funding

None.

Conflict of Interest

None declared.

\section{References}

1 Heald RJ, Husband EM, Ryall RD. The mesorectum in rectal cancer surgery-the clue to pelvic recurrence? Br J Surg 1982;69(10):613-616

2 Buess G, Theiss R, Günther M, Hutterer F, Pichlmaier H. Endoscopic surgery in the rectum. Endoscopy 1985;17(01):31-35

3 Buess G, Theiss R, Hutterer F, et al. [Transanal endoscopic surgery of the rectum - testing a new method in animal experiments]. Leber Magen Darm 1983;13(02):73-77 
4 Arezzo A, Arolfo S, Allaix ME, et al. Transanal endoscopic microsurgery for giant circumferential rectal adenomas. Colorectal Dis 2016;18(09):897-902

5 Buess G, Kipfmüller K, Naruhn M, Braunstein S, Junginger T. Endoscopic microsurgery of rectal tumors. Endoscopy 1987;19 (Suppl 1):38-42

6 de Graaf EJ, Burger JW, van Ijsseldijk AL, Tetteroo GW, Dawson I, Hop WC. Transanal endoscopic microsurgery is superior to transanal excision of rectal adenomas. Colorectal Dis 2011;13 (07):762-767

7 Clancy C, Burke JP, Albert MR, O'Connell PR, Winter DC. Transanal endoscopic microsurgery versus standard transanal excision for the removal of rectal neoplasms: a systematic review and metaanalysis. Dis Colon Rectum 2015;58(02):254-261

8 Baatrup G, Svensen R, Ellensen VS. Benign rectal strictures managed with transanal resection-a novel application for transanal endoscopic microsurgery. Colorectal Dis 2010;12(02): 144-146

9 D’Ambrosio G, Paganini AM, Guerrieri M, et al. Minimally invasive treatment of rectovaginal fistula. Surg Endosc 2012;26(02): 546-550

10 Bloemendaal AL, De Schepper M, Mishra A, et al. Trans-anal endoscopic microsurgery for internal rectal prolapse. Tech Coloproctol 2016;20(02):129-133

11 Arezzo A. To TEM or not to TEM: past, present and probable future perspectives of the transanal endoscopic microsurgery platform. Tech Coloproctol 2016;20(05):271-272

12 Lezoche E, Guerrieri M, Paganini AM, et al. Transanal endoscopic versus total mesorectal laparoscopic resections of T2-N0 low rectal cancers after neoadjuvant treatment: a prospective randomized trial with a 3-years minimum follow-up period. Surg Endosc 2005;19(06):751-756

13 Lezoche G, Baldarelli M, Guerrieri M, et al. A prospective randomized study with a 5-year minimum follow-up evaluation of transanal endoscopic microsurgery versus laparoscopic total mesorectal excision after neoadjuvant therapy. Surg Endosc 2008;22(02):352-358

14 Sajid MS, Farag S, Leung P, Sains P, Miles WF, Baig MK. Systematic review and meta-analysis of published trials comparing the effectiveness of transanal endoscopic microsurgery and radical resection in the management of early rectal cancer. Colorectal Dis 2014;16(01):2-14

15 Serra-Aracil X, Mora-Lopez L, Alcantara-Moral M, Caro-Tarrago A, Gomez-Diaz CJ, Navarro-Soto S. Transanal endoscopic surgery in rectal cancer. World J Gastroenterol 2014;20(33): 11538-11545

16 Veereman G, Vlayen J, Robays J, et al. Systematic review and metaanalysis of local resection or transanal endoscopic microsurgery versus radical resection in stage i rectal cancer: a real standard? Crit Rev Oncol Hematol 2017; 114:43-52

17 Chiniah M, Ganganah O, Cheng Y, Sah SK. Transanal endoscopic microsurgery is an oncologically safe alternative to total mesorectal excision for stage I rectal cancer: results of a meta-analysis of randomized controlled trials. Int J Colorectal Dis 2016;31(08): 1501-1504

18 Moher D, Liberati A, Tetzlaff J, Altman DGPRISMA Group. Preferred reporting items for systematic reviews and meta-analyses: the PRISMA statement. BMJ 2009;339:b2535

19 Jadad AR, Moore RA, Carroll D, et al. Assessing the quality of reports of randomized clinical trials: is blinding necessary? Control Clin Trials 1996;17(01):1-12

20 Hozo SP, Djulbegovic B, Hozo I. Estimating the mean and variance from the median, range, and the size of a sample. BMC Med Res Methodol 2005;5:13

21 Winde G, Nottberg H, Keller R, Schmid KW, Bünte H. Surgical cure for early rectal carcinomas (T1). Transanal endoscopic microsurgery vs. anterior resection. Dis Colon Rectum 1996;39(09):969-976
22 Lezoche E, Baldarelli M, Lezoche G, Paganini AM, Gesuita R, Guerrieri M. Randomized clinical trial of endoluminal locoregional resection versus laparoscopic total mesorectal excision for T2 rectal cancer after neoadjuvant therapy. Br J Surg 2012;99(09): 1211-1218

23 Chen YY, Liu ZH, Zhu K, Shi PD, Yin L. Transanal endoscopic microsurgery versus laparoscopic lower anterior resection for the treatment of T1-2 rectal cancers. Hepatogastroenterology 2013; 60(124):727-732

24 Burghardt J, Buess G. Transanal endoscopic microsurgery (TEM): a new technique and development during a time period of 20 years. Surg Technol Int 2005;14:131-137

25 Tytherleigh MG, Warren BF, Mortensen NJ. Management of early rectal cancer. Br J Surg 2008;95(04):409-423

26 Ortenzi M, Ghiselli R, Paolucci A, Guerrieri M. The feasibility of laparoscopic rectal resection in patients undergoing reoperation after transanal endoscopic microsurgery (TEM). Surg Endosc 2018;32(04):2020-2025

27 Park SM, Kye BH, Kim MK, Jalloun HE, Cho HM, Lee IK. Are we doing too much?: local excision before radical surgery in early rectal cancer Int J Colorectal Dis 2018;33(04):383-391

28 Ondhia M, Tamvakeras P, O'Toole P, et al; Merseyside Early Rectal Cancer Network. Transanal endoscopic microsurgery for rectal lesions in a specialist regional early rectal cancer centre: the Mersey experience. Colorectal Dis 2019;21(10):1164-1174

29 Peltrini R, Sacco M, Luglio G, Bucci L. Local excision following chemoradiotherapy in T2-T3 rectal cancer: current status and critical appraisal. Updates Surg 2020;72(01):29-37

30 Amann M, Modabber A, Burghardt J, et al. Transanal endoscopic microsurgery in treatment of rectal adenomas and T1 low-risk carcinomas. World J Surg Oncol 2012;10:255

31 Chang AJ, Nahas CS, Araujo SE, et al. Early rectal cancer: local excision or radical surgery? J Surg Educ 2008;65(01):67-72

32 De Graaf EJ, Doornebosch PG, Tollenaar RA, et al. Transanal endoscopic microsurgery versus total mesorectal excision of T1 rectal adenocarcinomas with curative intention. Eur J Surg Oncol 2009;35(12):1280-1285

33 Ganai S, Kanumuri P, Rao RS, Alexander AI. Local recurrence after transanal endoscopic microsurgery for rectal polyps and early cancers. Ann Surg Oncol 2006;13(04):547-556

34 Whitehouse PA, Armitage JN, Tilney HS, Simson JN. Transanal endoscopic microsurgery: local recurrence rate following resection of rectal cancer. Colorectal Dis 2008;10(02):187-193

35 McCloud JM, Waymont N, Pahwa N, et al. Factors predicting early recurrence after transanal endoscopic microsurgery excision for rectal adenoma. Colorectal Dis 2006;8(07):581-585

36 Doornebosch PG, Ferenschild FT, de Wilt JH, Dawson I, Tetteroo GW, de Graaf EJ. Treatment of recurrence after transanal endoscopic microsurgery (TEM) for T1 rectal cancer. Dis Colon Rectum 2010;53(09):1234-1239

37 Stipa F, Giaccaglia V, Burza A. Management and outcome of local recurrence following transanal endoscopic microsurgery for rectal cancer. Dis Colon Rectum 2012;55(03):262-269

38 Dulskas A, Atkociunas A, Kilius A, Petrulis K, Samalavicius NE. Is previous transanal endoscopic microsurgery for early rectal cancer a risk factor of worse outcome following salvage surgery a case-matched analysis. Visc Med 2019;35(03):151-155

39 Levic K, Bulut O, Hesselfeldt P, Bülow S. The outcome of rectal cancer after early salvage TME following TEM compared with primary TME: a case-matched study. Tech Coloproctol 2013;17 (04):397-403

40 Weiser MR, Landmann RG, Wong WD, et al. Surgical salvage of recurrent rectal cancer after transanal excision. Dis Colon Rectum 2005;48(06):1169-1175

41 Friel CM, Cromwell JW, Marra C, Madoff RD, Rothenberger DA, Garcia-Aguílar J. Salvage radical surgery after failed local excision for early rectal cancer. Dis Colon Rectum 2002;45(07):875-879 
42 Issa N, Murninkas A, Schmilovitz-Weiss H, Agbarya A, Powsner E. Transanal endoscopic microsurgery after neoadjuvant chemoradiotherapy for rectal cancer. J Laparoendosc Adv Surg Tech A 2015;25(08):617-624

43 Rizzo G, Zaccone G, Magnocavallo M, et al. Transanal endoscopic microsurgery after neoadjuvant radiochemotherapy for locally advanced extraperitoneal rectal cancer. Eur J Surg Oncol 2017;43 (08):1488-1493

44 Creavin B, Ryan E, Martin ST, et al. Organ preservation with local excision or active surveillance following chemoradiotherapy for rectal cancer. Br J Cancer 2017;116(02):169-174

45 Guerrieri M, Gesuita R, Ghiselli R, Lezoche G, Budassi A, Baldarelli M. Treatment of rectal cancer by transanal endoscopic microsurgery: experience with 425 patients. World J Gastroenterol 2014 20(28):9556-9563

46 Stijns RCH, de Graaf EJR, Punt CJA, et al; CARTS Study Group. Longterm oncological and functional outcomes of chemoradiotherapy followed by organ-sparing transanal endoscopic microsurgery for distal rectal cancer: the CARTS study. JAMA Surg 2019;154(01): 47-54

47 van Heinsbergen M, Leijtens JW, Slooter GD, Janssen-Heijnen ML, Konsten JL. Quality of life and bowel dysfunction after transanal endoscopic microsurgery for rectal cancer: one third of patients experience major low anterior resection syndrome. Dig Surg 2020;37(01):39-46

48 Lezoche E, Paganini AM, Fabiani B, et al. Quality-of-life impairment after endoluminal locoregional resection and laparoscopic total mesorectal excision. Surg Endosc 2014;28(01): 227-234

49 Marques CF, Nahas CS, Ribeiro U Jr, et al. Postoperative complications in the treatment of rectal neoplasia by transanal endoscopic microsurgery: a prospective study of risk factors and time course. Int J Colorectal Dis 2016;31(04):833-841

50 Beets GL, Figueiredo NF, Beets-Tan RG. Management of rectal cancer without radical resection. Annu Rev Med 2017; $68: 169-182$ 